\title{
Reception of textiles with antibacterial properties by stilbene dye usage
}

\author{
Sergey Efanov ${ }^{1 *}$, Tatyana Kudryavtseva ${ }^{l}$, Larisa Atrepieva ${ }^{1}$, Lyudmila Klimova ${ }^{2}$, Ilona \\ Kometiani $^{l}$ and Irina Oleynikova ${ }^{3}$ \\ ${ }^{1}$ Kursk State University, 305000, Kursk, Russia; \\ ${ }^{2}$ Kursk State Medical University, 305000, Kursk, Russia, \\ ${ }^{3}$ Belgorod State National Research University, 308015, Belgorod, Russia
}

\begin{abstract}
The possibility of imparting an antibacterial effect to cellulose tissue dyed with the product of azo coupling of diazotized 4,4'diaminostilbene-2,2'-disulfonic acid with 8-hydroxyquinoline has been shown. It was found that fabrics dyed by fixing the dye with a silver salt have a significant antibacterial effect, which lasts at least 10 washings. Keywords: antibacterial properties, stilbene dye, textiles with antibacterial properties,
\end{abstract}

\section{Introduction}

Currently the market is widely represented by fabrics of various compositions, modified with silver nanoparticles or containing silver threads in the structure. The manufacture of such tissues comes with additional technological and raw material costs [1,2]. The case of interest is to study the possibility of giving fabrics the similar effect directly at dyeing stage by applying dyes that exhibit antiseptic activity or fixing mordant dyes by salts of bioactive 's metal. It is known that azoic dye based on 8-hydroxyquinoline shows antibacterial and antifungal properties. The combination of 8-hydroxyquinoline with diazotized 4,4'diaminostilbene-2,2'-disulphonic acid permits to get substantive dye, capable to form on the fiber complexes with metal ions [3].

\section{Materials and methods}

Synthesis of 4,4'-bis(8-hydroxyquinoline-5-il)diazenil)stilbene-2,2'-disulphonic acid. In beaker with $50 \mathrm{ml}$ volume was prepared sodium carbonate solution $(0,1 \mathrm{~mol})$ in water $(5$ $\mathrm{ml}$ ) in which was solubilized 4,4'-diaminostilbene-2,2'-disulphonic acid (0,1 mol). After dissolution to the mixture was added $0,3 \mathrm{~mol}$ of $35 \%$ hydrochloric acid. The reaction mixture was cooled by ice and portionwise was added 0,2 mol of sodium nitrite. The reaction time is 30 minutes. Then derived suspension of diazonium salt was portionwise added to cooled alkaline solution of $0,2 \mathrm{~mol} 8$ - hydroxyquinoline. The reaction was carried

\footnotetext{
* Corresponding author: 1abos@kursksu.ru
} 
out at $\mathrm{pH}=8,0-8,5$. The reaction duration is 1 hour. At the end of the reaction was added $35 \%$ hydrochloric acid solution to the reaction mixture until getting $\mathrm{pH}=4,5-5,0$. The precipitate that formed was filtered under vacuum, washed with water and dried in air.

The dye yield was $88 \%$ of theoretical.

IR-spectrum $(\mathrm{KBr}), v\left(\mathrm{~cm}^{-1}\right): 3400(\mathrm{O}-\mathrm{H}) ; 1630(\mathrm{C}=\mathrm{N}) ; 1588-1551 \quad\left(\mathrm{C}=\mathrm{C}_{\mathrm{ap}}\right) ; 1451$ $(\mathrm{N}=\mathrm{N}) ; 1357\left(\mathrm{C}-\mathrm{SO}_{3} \mathrm{H}\right) ; 1111(\mathrm{~S}=\mathrm{O})$.

Mass-spectrum m/z $683[\mathrm{M}+\mathrm{H}]^{+}$; counted for $\mathrm{C}_{32} \mathrm{H}_{22} \mathrm{~N}_{6} \mathrm{O}_{8} \mathrm{~S}_{2} 682$.

Infrared spectra were recorded on FTIR spectrometer FSM 1201 (company Monitoring) in a $\mathrm{KBr}$ pellet in the range of wave numbers $400-4000 \mathrm{~cm}^{-1}$.

Liquid chromatography with mass spectrometric detection was performed using an ACQUITY UPLC H-Class system with UV/mass detectors ACQUITY SQD from Waters company. Gradient elution in the system: aqueous solution of ammonium bicarbonate 10 $\mathrm{mm}(\mathrm{pH} 8,4) /$ acetonitrile. Ionization in electrospray with detection of the positive ions current.
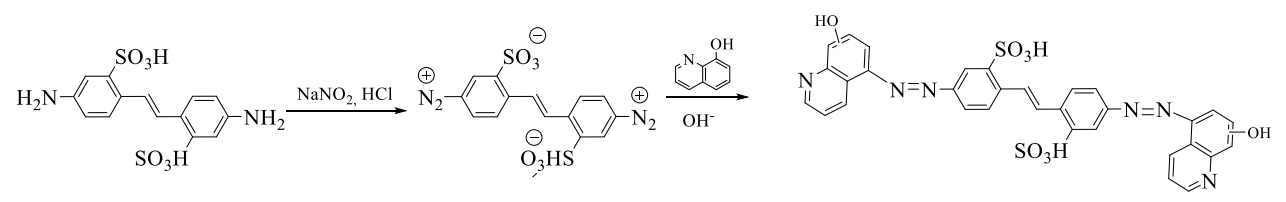

Fig. 1. Scheme of synthesis of 4,4'-bis (8-hydroxyquinolin-5-yl) diazenyl) stilbene-2,2'-disulfonic acid

The method of direct dyeing from aqueous solutions was used for dyeing of cellulose fiber fabric:

- bath module 50;

- the dye concentration is $0.02 \%$ of the textile material weight;

- the amount of sodium chloride is $2 \%$ of the textile material weight.

The temperature regime of processing within the boundaries of standard technological modes of dyeing with substantial dyes.

The processing of stained fabric samples with copper and zinc salts and silver was carried out under the following conditions:

- the required amount of salts was calculated depending on the weight of the processed fabric based on the possibility of the formation of a dye-metal complex with a composition of 1: 2 ;

- bath module 25 ;

- temperature rise from 25 to 100 degrees Celsius - 10-15 minutes;

- exposure at the boiling point of the bath - $5 \mathrm{~min}$;

- exposure on a cooling bath - $20 \mathrm{~min}$;

- flushing to clean flushing water without the detergents use.

To study the antimicrobial activity were used fabric discs of 10,0 mm diameter, which after sterilization were placed on the surface of a sterile agar medium previously inoculated with the appropriate microorganism.

\section{Results and discussions}

For the product of the azocoupling reaction of diazotized 4,4'-diaminostilbene-2,2'disulphonic acid with 8-hydroxyquinoline was established the formation of two isomers, due to the combination of 8-hydroxyquinoline at positions 5 and 7. For subsequent dyeing the resulting mixture of dye isomers was used without preliminary division.

The synthesized product under the above conditions dyes the fabric in a violet-pink color. When the dye is fixed with zinc-copper-silver salts no significant color change is 
observed. Lack of a significant change in color that is consistent with the classical concepts of the structure complexes, the formation of which does not affect the chromophore system of the dye.

There is no growth of pathogenic microorganisms' colonies within the boundaries of a fabric fragment, stained with the synthesized dye, that was in contact with a pre-seeded nutrient medium. Subsequent exposure of the dyed fabric with copper and zinc salts at the studied concentrations, does not lead to antibacterial activity increase. Exposure of dyed fabrics with silver nitrate leads to a significant increase in antibacterial activity, which persists for at least 10 washes with the use of household detergents. The research results are shown in table 1.

Table 1. Diameter of zones of microorganisms' test strains growth retardation by fabric fragment dyed with an azocoupling product with further fixation by metal salts

\begin{tabular}{|c|c|c|c|c|c|c|}
\hline $\begin{array}{c}\text { Sample } \\
\text { No. }\end{array}$ & $\begin{array}{c}\text { E. coli } \\
\text { (ATCC } \\
\text { 25922) }\end{array}$ & $\begin{array}{c}\text { Ps. } \\
\text { aeruginosa } \\
\text { (ATCC } \\
\text { 27853) }\end{array}$ & $\begin{array}{c}\text { Pr.vulgaris } \\
\text { (ATCC } \\
\text { 4636) }\end{array}$ & $\begin{array}{c}\text { S. aureus } \\
\text { (ATCC } \\
\text { 25923) }\end{array}$ & $\begin{array}{c}\text { B.subtilis } \\
\text { (ATCC } \\
\text { 6633) }\end{array}$ & $\begin{array}{c}\text { Candida } \\
\text { albicans } \\
\text { (NCTC } \\
\text { 2625) }\end{array}$ \\
\hline 0 & \multicolumn{6}{|c|}{$-1000)$} \\
\hline 1 & \multirow{3}{*}{\multicolumn{6}{|c|}{10,0}} \\
\hline 2 & & & & & & \\
\hline 3 & & & & & & \\
\hline 4 & $19,0 \pm 0,4$ & $23,0 \pm 0,6$ & $19,0 \pm 0,4$ & $24,5 \pm 0,5$ & $15,5 \pm 0,4$ & $15,5 \pm 0,3$ \\
\hline 5 & $11,0 \pm 0,3$ & $22,5 \pm 0,5$ & $17,0 \pm 0,3$ & $24,0 \pm 0,6$ & $12,5 \pm 0,3$ & $13,0 \pm 0,3$ \\
\hline 6 & $12,0 \pm 0,3$ & $18,0 \pm 0,5$ & $17,0 \pm 0,4$ & $24,0 \pm 0,6$ & $12,5 \pm 0,2$ & $12,0 \pm 0,2$ \\
\hline 7 & $10,5 \pm 0,2$ & $15,0 \pm 0,4$ & $15,5 \pm 0,3$ & $24,0 \pm 0,5$ & $15,5 \pm 0,4$ & $14,0 \pm 0,4$ \\
\hline
\end{tabular}

0 - original unpainted fabric; 1 - fabric dyed using direct dyeing technology; 2 - fixation with zinc salt; 3 - fixation with copper salt; 4 - fixation with silver salt; 5 - fabric "4" after one wash; 6 - fabric "4" after five washes; 7 fabric "4" after 10 washes.

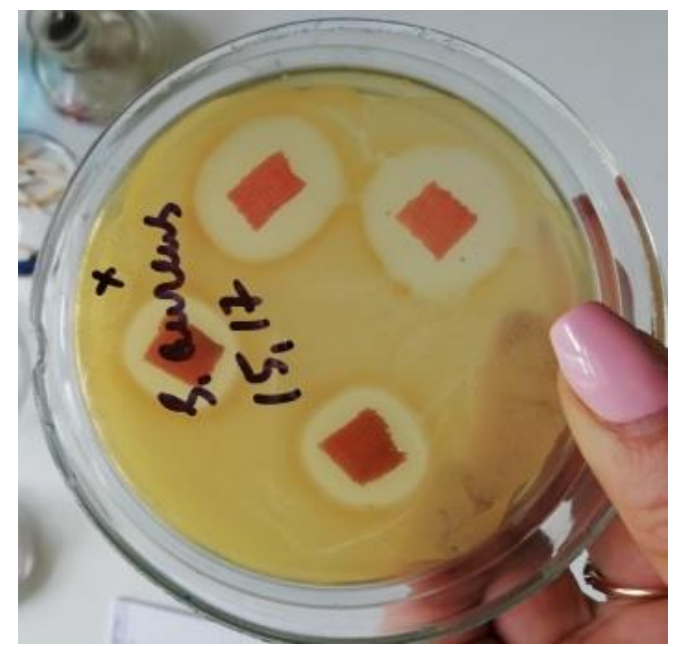

Fig. 2. Growth retardation of S. aureus colonies by fragments of dyed fabric, with fixations with silver salt.

During storage of the fabric treated with silver nitrate, slight change in the original color was observed with the appearance of a grayish-black tone that disappeared during washing. The observed phenomenon was associated by us with the destruction of silver complexes, accompanied by the formation of colloidal silver or its dark-colored salts, for example, sulfides. 
To test this hypothesis, the tissue fragments were examined using an electron scanning microscope and the elemental composition of the material was determined. The study showed the presence of non-uniformly distributed agglomerates of particles on the fibers' surface, in the elemental composition of which was found the presence of silver and sulfur (Fig. 3). It should be noted that a similar study was carried out immediately after processing the dyed fabric did not reveal such agglomerates.

This fact indicates the relative instability of the silver complexes formed on the fiber, which, however, does not reduce the antibacterial activity displayed by the fabric.
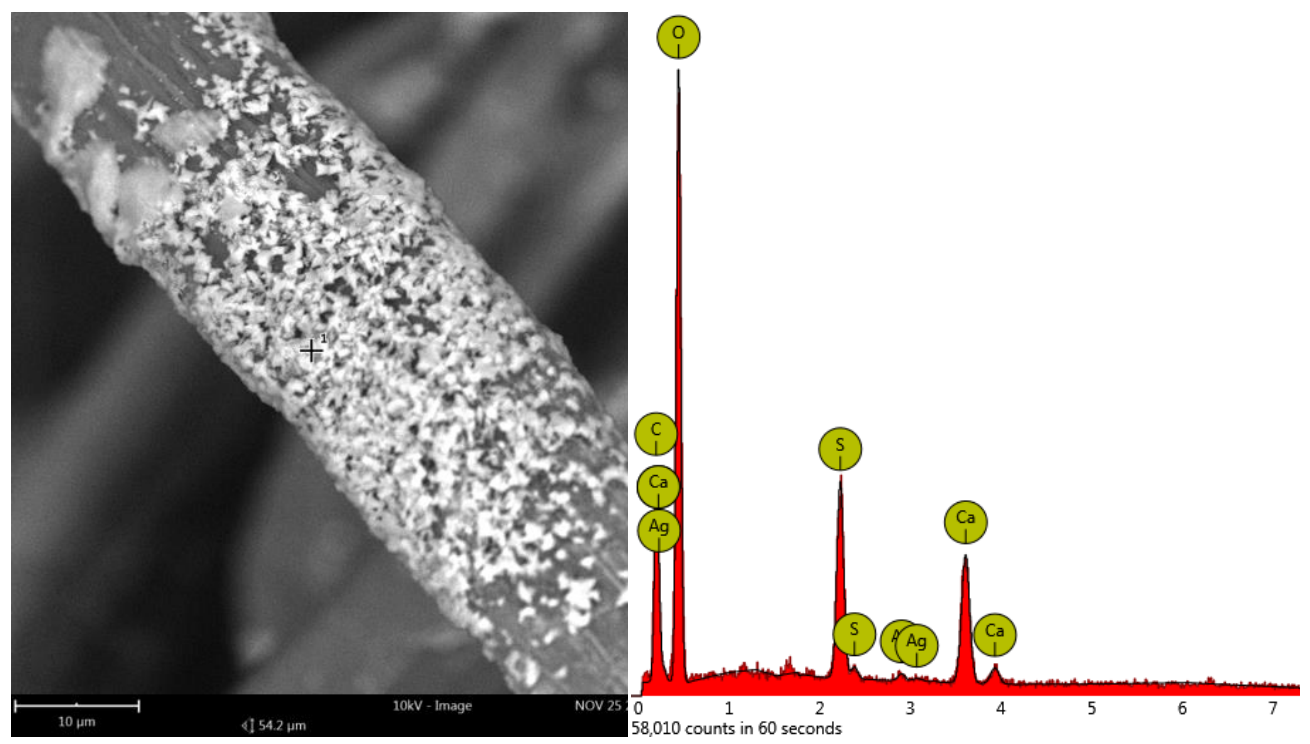

Fig.3. Agglomerates of silver and sulfur compounds formed on the surface of the fibers of the treated fabric

\section{Conclusions}

The studies have shown the potential of imparting an antibacterial effect to cellulose fabric within the dyeing technological condition with substantive dyes. For fabric dyed with the product of azocoupling of diazotized 4,4'-diaminostilbene-2,2'-disulphonic acid with 8hydroxyquinoline, there is no growth of colonies of pathogenic microorganisms' test strains within the boundaries of a fabric fragment in contact with a pre-seeded nutrient medium. Fabrics dyed with dye fixation with silver salt exhibit a significant antibacterial effect that lasts for at least 10 washes.

\section{References}

1. B. R. Tausarova, S. M. Rakhimova, Khimija rastitel'nogo syr'ja, 2 (2020) DOI 10.14258/jcprm. 2020025986 (2020)

2. Patent № 2525545 C2 Russian Federation, MPK D01F 11/02, D06B 1/00, D06M 23/00. Method of production of antimicrobial argentiferous cellulosic material : № 2012141671/05 : stated 02.10.2012 : published 20.08.2014 / N. S. Dymnikova, E. V. Erokhina, P. A. Moryganov [and others] ; applicant OOO "Innovatsionnii technologii l'nopererabotki". 
3. L. V. Atrepyeva, T. N. Kudryavtseva, M. S. Annenkova. Problems of theoretical and experimental chemistry, 52 (2018) 